\title{
Editorial: Epistemic Feelings: Phenomenology, Implementation, and Role in Cognition
}

\author{
Eric Dietrich ${ }^{1 \dagger}$, Chris Fields ${ }^{2 * t}$, Donald D. Hoffman ${ }^{3}$ and Robert Prentner ${ }^{3+}$ \\ ${ }^{1}$ Department of Philosophy, Binghamton University, Binghamton, NY, United States, ${ }^{2}$ Independent Researcher, \\ Caunes-Minervois, France, ${ }^{3}$ Department of Cognitive Science, University of California, Irvine, Irvine, CA, United States
}

Keywords: belief, knowing, familiarity, agency, confidence

\section{Editorial on the Research Topic}

\section{OPEN ACCESS}

Edited by:

Anna M. Borghi,

Sapienza University of Rome, Italy

Reviewed by:

Sara Dellantonio,

University of Trento, Italy

${ }^{*}$ Correspondence:

Chris Fields

fieldsres@gmail.com

TORCID:

Eric Dietrich

orcid.org/0000-0002-1410-0307

Chris Fields

orcid.org/0000-0002-4812-0744

Robert Prentner

orcid.org/0000-0003-1890-0827

Specialty section:

This article was submitted to

Theoretical and Philosophical

Psychology,

a section of the journal

Frontiers in Psychology

Received: 14 September 2020

Accepted: 30 September 2020

Published: 27 October 2020

Citation:

Dietrich E, Fields C, Hoffman DD and

Prentner R (2020) Editorial: Epistemic

Feelings: Phenomenology,

Implementation, and Role in

Cognition. Front. Psychol. 11:606046.

doi: 10.3389/fpsyg.2020.606046
Epistemic Feelings: Phenomenology, Implementation, and Role in Cognition

Epistemic feelings, including feelings of familiarity, knowledge, belief, confidence, doubt, confusion, curiosity, agency, ownership, and many others, are ubiquitous components of human experience (Arango-Muñoz, 2014; Proust, 2015). Such feelings are distinct from canonical emotions, yet appear to play similar motivational and regulative roles in cognition, particularly in deliberative, reportable, "process-2" cognition (Evans, 2008; Evans and Stanovich, 2013; see Melnikoff and Bargh, 2018 for criticism of the dual-process distinction). They are the experienced and reportable "propositional attitudes" of folk psychology and pre-computational cognitive representationalism (Fodor, 1978).

Despite their phenomenological ubiquity and historical importance, epistemic feelings are rarely treated as a coherent class of experiences, and relatively little is known about their implementation or their motivational or regulatory roles. Consider, for example, the development of Theory of Mind (ToM) research since Premack and Woodruff (1978). When and how beliefs are attributed to others and the effects of such attributions on the behavior (including verbal reports) of the attributor have been intensively investigated, particularly in children as they develop ToM abilities and in children and adults with impaired ToM abilities (for reviews, see Carlson et al., 2013; Singer and Tusche, 2014). How the "feeling of believing" is generated, however, and how it differs at the neural implementation level from the "feeling of knowing" remain unclear. From a phenomenological perspective, believing and knowing differ in, among other things, felt confidence. While feelings of confidence appear to involve activity in the insulate-cingulate-medial-prefrontal loop (Craig, 2009; Dajani and Uddin, 2015), how they exert their regulatory functions, and how the regulatory roles of "belief" and "knowledge" differ, similarly remain unclear.

Despite the relative lack of investigation of epistemic feelings as a class, considerable information is available about some epistemic feelings considered in isolation. The implementation and functional consequences of feelings of familiarity, for example, have been extensively studied in the visual modality (e.g., Yonelinas et al., 2010). Feelings of confidence in perceptual judgments have been shown to overestimate evidence for the chosen interpretation by discounting evidence for alternatives (Peters et al., 2017). Feelings of agency and ownership have been associated with the medial prefrontal "reality monitoring" system, in part due to their common disruption in schizophrenia (e.g., Simons et al., 2017). Feelings of autonoetic certainty have been mapped to insular cortex in part due to their prevalence in insular-cortex seizures (e.g., Gschwind and Picard, 2016). 
The papers in this Research Topic exhibit the eclectic nature of the field. The single experimental paper, by Vogl et al. replicates and extends findings from an earlier study (Vogl et al., 2020) of associations between epistemic feelings (surprise, curiosity, and confusion) and emotions (pride and shame) following successful or unsuccessful completion of a task. They show, in particular, that the epistemic feelings investigated, but not the corresponding emotions, correlate with and possibly motivate knowledge seeking. Cornwall and Higgins review evidence suggesting that epistemic feelings of knowledge (truthfulness) and agency (ability to control) combine with moral feelings to motivate moral judgments and decision making. Perrin et al. consider a particular aspect of autonoetic awareness, the feeling of pastness, and propose that this epistemic feeling contributes to "tagging" some experiences as experiences of a personal past, i.e., as episodic memories. Chang et al. adopt a more abstract approach to experience, arguing from informationtheoretic assumptions that events are only experienced (i.e., are only reportably conscious) if their neural implementation is informationally closed, i.e., is sufficient to predict its own future state from its current state as well as that of its environment. In this model, it would be natural to consider epistemic feelings as experienced indicators of predictability, a view compatible with that of predictive-coding models (e.g., Clark, 2013). Levin takes an even bolder step, arguing from considerations of cell and developmental biology that the concepts of "self" and "agency" can and should be extended to the levels of individual cells and functionally-coherent tissues. In this model of "scalefree cognition," epistemic feelings are components of actionable representations of the environmentally-embedded self not just at the individual-organism scale, but at both smaller and larger scales as well.

In a critical review of the role of "factors" and models across psychology, Jolly and Chang (2019) argue that formalized, quantitative, high-dimensional models capable of integrating data from multiple experiments are needed to move psychology forward. Even in its current, fragmentary

\section{REFERENCES}

Arango-Muñoz, S. (2014). The nature of epistemic feelings. Philos. Psychol. 27, 193-211. doi: 10.1080/09515089.2012.732002

Carlson, S. M., Koenig, M. A., and Harms, M. B. (2013). Theory of mind. WIRES Cogn. Sci. 4, 391-402. doi: 10.1002/wcs.1232

Clark, A. (2013). Whatever next? predictive brains, situated agents, and the future of cognitive science. Behav. Brain Sci. 36, 181-204. doi: 10.1017/S0140525X12000477

Craig, A. D. (2009). How do you feel - now? The anterior insula and human awareness. Nat. Rev. Neurosci. 10, 59-70. doi: 10.1038/nrn2555

Dajani, D. R., and Uddin, L. Q. (2015). Demystifying cognitive flexibility: implications for clinical and developmental neuroscience. Trends Neurosci. 38, 571-578. doi: 10.1016/j.tins.2015.07.003

Dehaene, S., Charles, L., King, J.-R., and Marti, S. (2014). Toward a computational theory of conscious processing. Curr. Opin. Neurobiol. 25, 76-84. doi: 10.1016/j.conb.2013.12.005

Evans, J. St. B. T. (2008). Dual processing accounts of reasoning, judgement and social cognition. Annu. Rev. Psychol. 59, 255-278. doi: 10.1146/annurev.psych.59.103006.093629 state, our understanding of epistemic feelings suggests that they will play central roles in such models. Questions that appear empirically tractable include the following:

- What, in general, is the relationship between epistemic feelings and emotions? The work of Vogl et al. provides a model for addressing this question; how far can such techniques be extended? How are associations between epistemic feelings and emotions implemented? Are the consequences of dissociation pathological, as they appear to be in, e.g., Capgras syndrome (Hirstein and Ramachandran, 1997)?

- As noted earlier, epistemic feelings are most evident during canonical process- 2 cognition. What is their role in process1 cognition, and how do these roles relate? Fields and Glazebrook (2020) have proposed that in the context of a global neuronal workspace model (e.g., Dehaene et al., 2014), subjective probabilities reported during process -2 cognition can be understood as outputs of process- 1 cognition. Does this relationship between reportable epistemic feelings and underlying automated processes generalize?

- What is the role of epistemic feelings in predictive processing models? Seth and Tsakiris (2018) have argued that the feeling of being an embodied self that is continuous through time is an experiential correlate of an interoceptive predictive-processing loop. Does this correlation generalize? How does it relate to the feeling of "pastness" studied by Perrin et al.?

As questions such as these begin to be answered, the role of epistemic feelings in both motivating and regulating cognition will become clearer. We expect that this role will prove to be a central one.

\section{AUTHOR CONTRIBUTIONS}

All authors listed have made a substantial, direct and intellectual contribution to the work, and approved it for publication.

Evans, J. St. B. T., and Stanovich, K. E. (2013). Dual-process theories of higher cognition: advancing the debate. Perspect. Psychol. Sci. 8, 223-241. doi: $10.1177 / 1745691612460685$

Fields, C., and Glazebrook, J. F. (2020). Do Process-1 simulations generate the epistemic feelings that drive Process-2 decision making? Cogn. Proc. doi: 10.1007/s10339-020-00981-9. [Epub a head of print].

Fodor, J. A. (1978). Propositional attitudes. Monist 61, 501-523. doi: 10.5840/monist197861444

Gschwind, M., and Picard, F. (2016).Ecstatic epileptic seizures: a glimpse into the multiple roles of the insula. Front. Behav. Neurosci. 10:21. doi: 10.3389/fnbeh.2016.00021

Hirstein, W., and Ramachandran, V. S. (1997). Capgras syndrome: a novel probe for understanding the neural representation of the identity and familiarity of persons. Philos. Trans. R. Soc. Lond. B 264, 437-444. doi: 10.1098/rspb.1997. 0062

Jolly, E., and Chang, L. J. (2019). The Flatland fallacy: moving beyond lowdimensional thinking. Top. Cogn. Sci. 11, 433-454. doi: 10.1111/tops.12404

Melnikoff, D. E., and Bargh, J. A. (2018). The mythical number two. Trends Cogn. Sci. 22, 280-293. doi: 10.1016/j.tics.2018.0 2.001 
Peters, M. A. K., Thesen, T., Ko, Y. D., Maniscalco, B., Carlson, C., Davidson, M., et al. (2017). Perceptual confidence neglects decision-incongruent evidence in the brain. Nat. Hum. Behav. 1:0139. doi: 10.1038/s41562-017-0139

Premack, D., and Woodruff, G. (1978). Does the chimpanzee have a theory of mind? Behav. Brain Sci. 4, 515-526. doi: 10.1017/S0140525X00076512

Proust, J. (2015). "The representational structure of feelings," in Open MIND 31, eds T. Metzinger and J. M. Windt (Frankfurt am Main: MIND Group), 25. doi: $10.15502 / 9783958570047$

Seth, A. K., and Tsakiris, M. (2018). Being a beast machine: the somatic basis of selfhood. Trends Cogn. Sci. 22, 969-981. doi: 10.1016/j.tics.2018.08.008

Simons, J. S., Garrison, J. R., and Johnson, M. K. (2017). Brain mechanisms of reality monitoring. Trends Cogn. Sci. 21, 462-473. doi: $10.1016 /$ j.tics.2017.03.012

Singer, T., and Tusche, A. (2014). "Understanding others: brain mechanisms of theory of mind and empathy," in Neuroeconomics, 2nd Edn, eds P. W. Glimcher and E. Fehr (Cambridge, MA: Academic Press, 513-532. doi: 10.1016/B978-0-12-416008-8.00 027-9
Vogl, E., Pekrun, R., Murayama, K., and Loderer, K. (2020). Surprised-curiousconfused: Epistemic emotions and knowledge exploration. Emotion 20, 625-641. doi: 10.1037/emo0000578

Yonelinas, A. P., Aly, M., Wang, W.-C., and Koen, J. D. (2010). Recollection and familiarity: examining controversial assumptions and new directions. Hippocampus 20, 1178-1194. doi: 10.1002/hipo.20864

Conflict of Interest: The authors declare that the research was conducted in the absence of any commercial or financial relationships that could be construed as a potential conflict of interest.

Copyright $\odot 2020$ Dietrich, Fields, Hoffman and Prentner. This is an open-access article distributed under the terms of the Creative Commons Attribution License (CC $B Y)$. The use, distribution or reproduction in other forums is permitted, provided the original author(s) and the copyright owner(s) are credited and that the original publication in this journal is cited, in accordance with accepted academic practice. No use, distribution or reproduction is permitted which does not comply with these terms. 